\title{
The Effect of the Smart Navigation System Based on Augmented Reality
}

\author{
Kunyanuth Kularbphettong, Ausanee Singkoo, Phanu Waraporn
}

\begin{abstract}
Currently, virtual technology is applied to everyday life. AR (Augmented Reality) has widely become a challenger technology that brings virtual $3 D$ images into the real world through a camera. Augmented Reality is a technology that brings virtual images that is a $3 \mathrm{D}$ model simulated into the real world through cameras and processing that brings objects to overlap into one image and $A R$ can help people to understand the content easily. Hence, in increasing the efficiency of services and publicizing various information, this paper presents the smart navigation system using augmented reality based on a smartphone in the case study of Benjakitti Park, Thailand. The application can navigate users to the POI destination and the system based on mobile devices is composed of two parts: the navigation application and the bone collector game. This project produced user satisfaction at a good level and the proposed application was able to support the significant information for navigation in aspects of performance, usability, and effectiveness.
\end{abstract}

Keywords : navigation system, augmented reality, smartphone, location-based.

\section{INTRODUCTION}

Augmented Reality technology (AR) is a virtual world designed to enhance user experience. Nowadays, AR is used in our daily lives whether playing games, learning the lessons or applying in social media applications like Instagram, Facebook and etc. Pokemon Go is a big phenomenon for gamers around the world that allows players to find and catch Pokémon around nearby [1]. The principle working of Augmented Reality technology is coordinated with many hardware parts such as camera, compass, GPS and accelerometer and there can be categorized to be 3 types which are Marker-based AR, Marker-less AR, and Location-based AR. Augmented Reality plays an important role in applying to various applications such as the medical industry, marketing, entertainment, tourism, and etc.

In the tourism sector, the main challenge of using augmented reality technology is to allow tourists to

Revised Manuscript Received on December 30, 2019.

* Correspondence Author

Kunyanuth Kularbphettong*, Assistant Professor, Faculty of Science and Technology, Suan Sunandha Rajabhat University. Thailand.

(e-mail: kunyanuth.ku@ssru.ac.th).

Ausanee Singkoo is the Developer of AIS Company. (E-mail: ausanee.si@gmail.com)

Phanu Waraporn, Lecturer, Computer Science Program, Faculty of Science and Technology, Suan Sunandha Rajabhat University. Thailand. (E-mail: phanu.wa@ssru.ac.th).

(C) The Authors. Published by Blue Eyes Intelligence Engineering and Sciences Publication (BEIESP). This is an open access article under the CC BY-NC-ND license (http://creativecommons.org/licenses/by-nc-nd/4.0/) experience the interesting places. Nowadays, many countries have started using AR for promotion tourism like Canada, Australia. Tourists can use their mobile devices such as smartphones or tablets to look at the marker provided on

various media such as brochures, signboards, tourist attractions, etc. and visitors will get information in various aspects such as static text, animated regions, sound and 3D animated models combined with the ability to interact with the user. Benchakitti Park is one of the most popular public parks in the city center, Bangkok, created in honor of Queen Sirikit. The park offers a health park, a children's playground and Bicycle tracks for everyone who needs to escape from the chaos in the city [2]. With the Advance of mobile phone and AR technology, the use of mobile has increased every year especially Thailand. Mobile devices can facilitate the publicity of tourist information and give related travel information to target areas. Hence, this project was developed a smart navigation application using augmented reality in the case of Benjakitti Park to provide and give information for users to make a route around the park.

\section{LITERATURE REVIEW}

The project was studied with the following related research: Augmented reality plays a significant role to enhance a user's interaction and much research has been conducted in aspects of how to develop AR application [3]-[5]. Pokémon Go is a game developed using AR (Augmented Reality) technology, which simulates both the real world and the game world, and allows users to hunt virtual creatures in the real [6]. The applications have explored the benefits of AR in various fields especially in the manufacturing environment to guide and give content instead of the outdated manual [7]. GPS (global positioning system) is employed in a Marker-less navigation system to provide location information however GPS enables well to identify in the outdoors. The indoor positioning navigation system is an advent technology to indicate the target position through smart mobile devices. According to research conducted by $\mathrm{U}$. Rehman and S. Cao, it is found that the time spent on using indoor navigation systems was shorter when compared to using paper maps. Also, the prototype of navigation was proposed to develop the simulated physical shopping mall environment based AR. ARToolkit was applied to use in the indoor environment with a wireless marker through image processing [9] and ARToolkit markers were used in many applications to track and location information [10]-[12]. Mapbox API is employed to develop the augmented reality navigation application based on tilesets instead of the traditional GPS signal navigation [13]. 
From the previous studies, the evidence shown that AR could support and develop in a wide range of work domains.

\section{SYSTEM DEVELOPMENT}

To implement the proposed smart navigation system using AR technology, a case study of Benjakitti Park, the project was divided the operating procedures in the analysis, design and development of the system, which had operations in accordance with the following steps: System Requirements Analysis; System Design and Program development.

\section{A. System Requirements Analysis}

To collect data and information in requirement analysis phase, the researchers studied related documents and research in AR and virtual technology. From the survey and questioning users in the park, it was found that when wanting to walk to various points inside the Benjakitti Park, they must look for the attached sign at the entrance. The map will present the overview of the park and moreover, some signs were damaged and causing those who use the service to not know where to go. Therefore, from studying the previous problems, this project was implemented and applied AR technology to be a benefit for users who use the service and exercise at Benjakitti Park.

\section{B. System Design}

In the system design phase, this section presents the system overview as shown in fig 1 which is divided into 3 parts: the navigation section, the game section, and the help section. To develop the smart navigation system using augmented reality, the first step is to indicate path generation to demonstrate the destination locations.

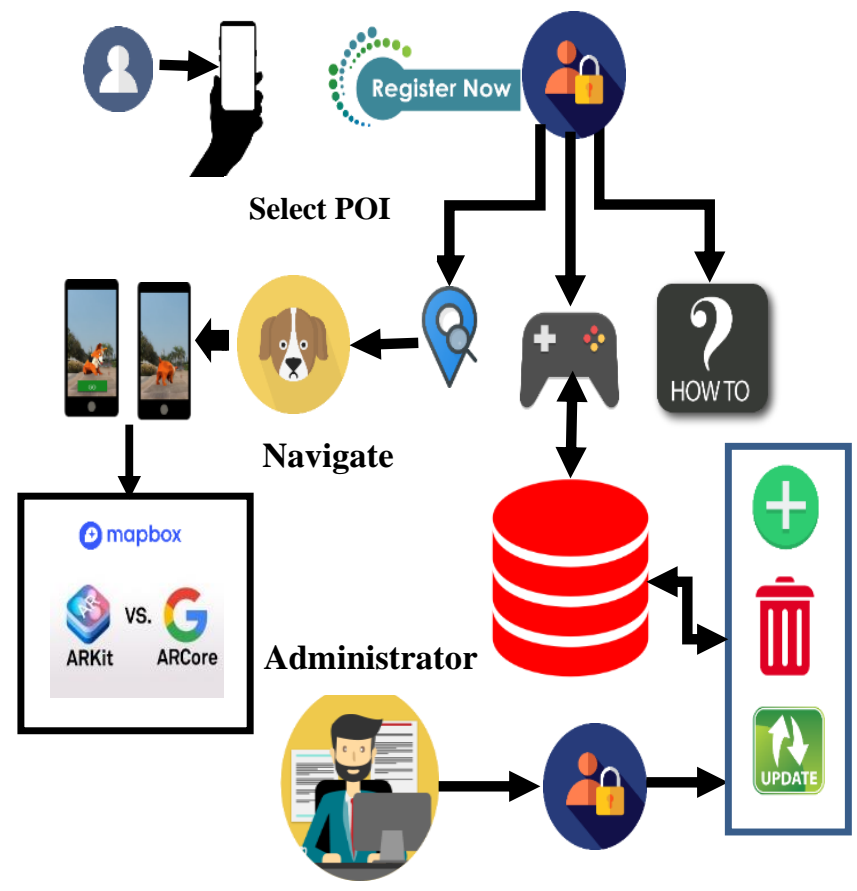

Fig. 1.The System Overview

In the navigation section, users can select a three-dimensional model to navigate to your destination and the system will display a three-dimensional model created by AR technology to guide you to your place. In the game section, users can play the game, like collecting bones, when finished playing the game, bones act as scores collected to the database in order to make a chance to get other 3D models. The help section plays a significant role to give and suggest users when using the application. Also, figure 2 was presented the database of this application.

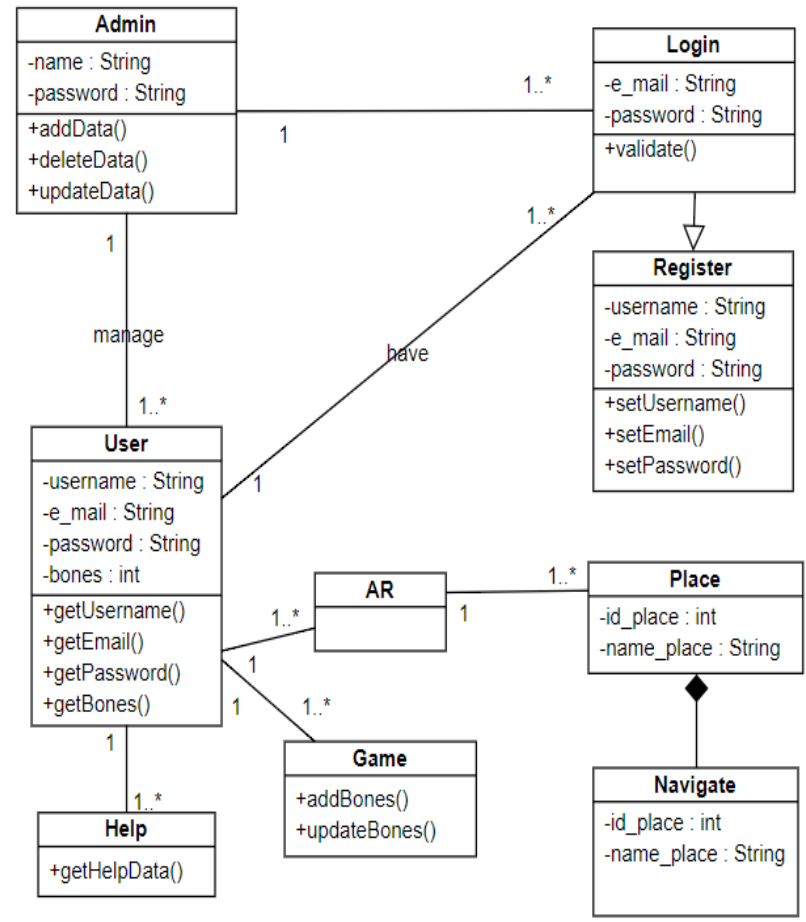

Fig. 2. The Database of the System

\section{System Implementation}

To implement the smart navigation system, there are many software programs like $\mathrm{C \#}$, and unity and the research determined 8 points of interest in this park. Mapbox was applied to build location-based on this project. There are two parts to develop this project: the administration phase based on the website and the navigation system based on the mobile device.

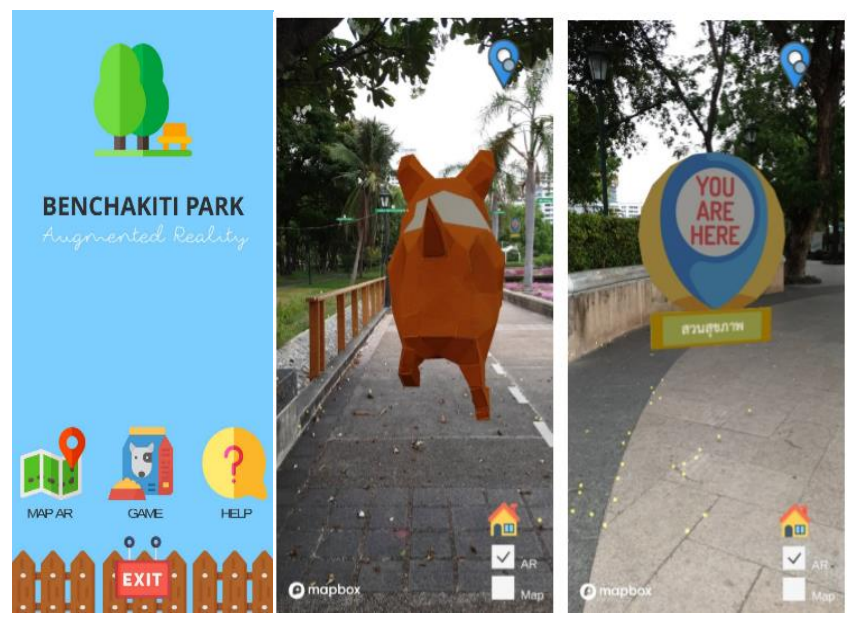

Fig. 3.The user interface screen in navigation section

Published By:

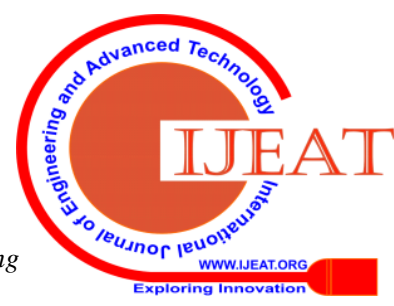


The navigation program operates when a user enters this application and chooses a 3D model and then the system will display the $3 \mathrm{D}$ model to navigate to user destination. The figure 3 and 4 were presented the user interface of this application.
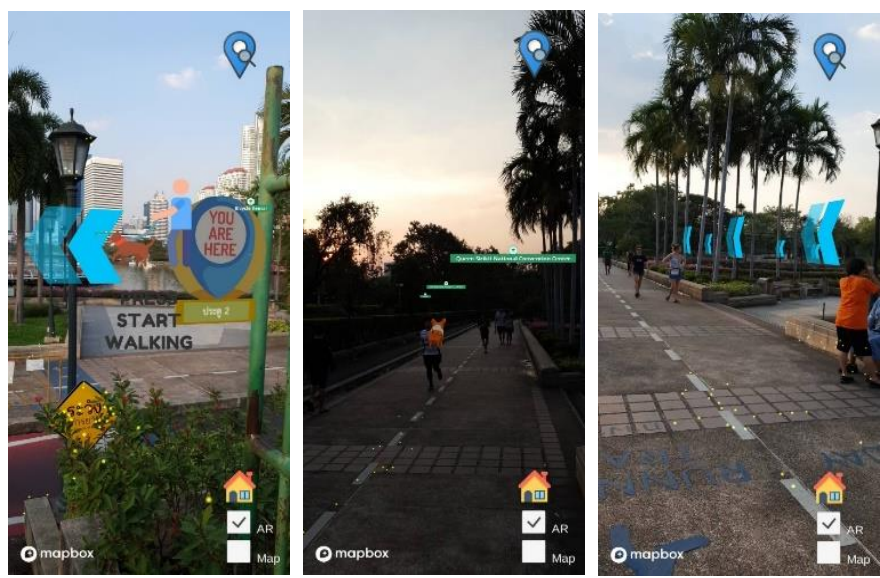

Fig. 4. The user interface in a navigation section

When a user enters the game section, a user is able to check the total number of bones that the user has collected and a user can change the 3D model if the amount of bone has accumulated enough as specified by the system as in Figure 5.
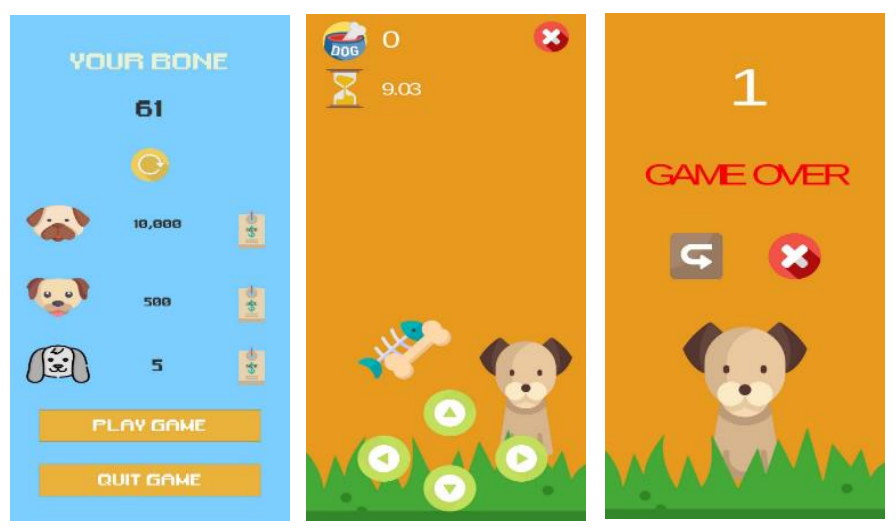

Fig. 5.The user interface in a game section

\section{RESULTS}

This research aims to develop the smart navigation system based on augmented reality and to assess the user satisfaction in the developed system Therefore, the presentation of the section is divided into 2 parts: part 1 is the part of the evaluation of the application performance and the last is the assessment of the user satisfaction.

\section{A. The evaluation of the application performance}

The software testing approach in this project was used the Black Box Testing, the significant software testing method applied to assess the functionality of a software or application by ignoring how the system works and how the software has been implemented [14]. Black Box Testing is widely adopted to test environments and this method consists of the following steps: function requirement test, functionality test, Usability testing, security testing and integrity test [15]-[16]. The function requirement test is an estimation of system functionality that meets the needs of users and the functional test is an assessment of system performance. A usability test is an evaluation of the ease of use of the system and a security test is an assessment of data security in the system. Also, integrity Test is a system integrity assessment.

The participants were 3 experts and 20 users for evaluation of this application. The interview and questionnaire were important tools for this assessment. When bringing AR applications for expert evaluation of AR applications, the results can be analyzed as displayed in Table I.

Table- I: The application performance

\begin{tabular}{|c|c|c|c|}
\hline & \multicolumn{3}{|c|}{ Level of Proficiency } \\
\hline & $\overline{\bar{X}}$ & SD & Result \\
\hline $\begin{array}{l}\text { 1. The Function requirement test } \\
1.1 \text { The appropriation of the } \\
\text { information presentation } \\
1.2 \text { The display is suitable for the } \\
\text { screen of various devices. }\end{array}$ & 4.55 & 0.72 & Highest \\
\hline $\begin{array}{l}\text { 2. The Functional Test } \\
2.1 \text { The ability to scan images }\end{array}$ & 4.75 & 0.50 & Highest \\
\hline $\begin{array}{l}\text { through mobile phones } \\
2.2 \text { The ability to display content }\end{array}$ & 3.75 & 0.50 & High \\
\hline $\begin{array}{l}2.3 \text { The ability to take pictures } \\
\text { and share images }\end{array}$ & 4.50 & 0.58 & High \\
\hline $\begin{array}{l}2.4 \text { The ability to get directions } \\
\text { to the destination }\end{array}$ & 4.00 & 0.82 & High \\
\hline $\begin{array}{l}\text { 3. The Usability Test } \\
\text { 3.1 Ease of use of the application }\end{array}$ & 4.00 & 0.82 & High \\
\hline $\begin{array}{l}3.2 \text { Suitability of tourist } \\
\text { attraction models }\end{array}$ & 3.75 & 0.50 & High \\
\hline $\begin{array}{l}3.3 \text { Suitability of movement of } \\
\text { tourist attraction models }\end{array}$ & 4.50 & 0.58 & High \\
\hline $\begin{array}{l}3.4 \text { Suitability of displaying } \\
\text { tourist attraction information }\end{array}$ & 4.50 & 0.58 & High \\
\hline $\begin{array}{l}\text { 3.5 Suitability of the screen } \\
\text { design }\end{array}$ & 4.50 & 0.58 & High \\
\hline $\begin{array}{l}\text { 4. The Security test } \\
4.1 \text { The system has protection }\end{array}$ & 4.13 & 0.75 & High \\
\hline $\begin{array}{l}\text { solutions. } \\
4.2 \text { User-defined operation }\end{array}$ & 4.30 & 0.46 & High \\
\hline $\begin{array}{l}\text { 5. The Integrity test } \\
5.1 \text { The system has complete and }\end{array}$ & 4.25 & 0.74 & High \\
\hline $\begin{array}{l}\text { complete components. } \\
5.2 \text { The system is creative. }\end{array}$ & 4.32 & 0.72 & High \\
\hline $\begin{array}{l}5.3 \text { The system has to search for } \\
\text { correct information. }\end{array}$ & 4.35 & 0.67 & High \\
\hline $\begin{array}{l}5.4 \text { The display is appropriate for } \\
\text { the screen size. }\end{array}$ & 4.12 & 0.68 & High \\
\hline
\end{tabular}

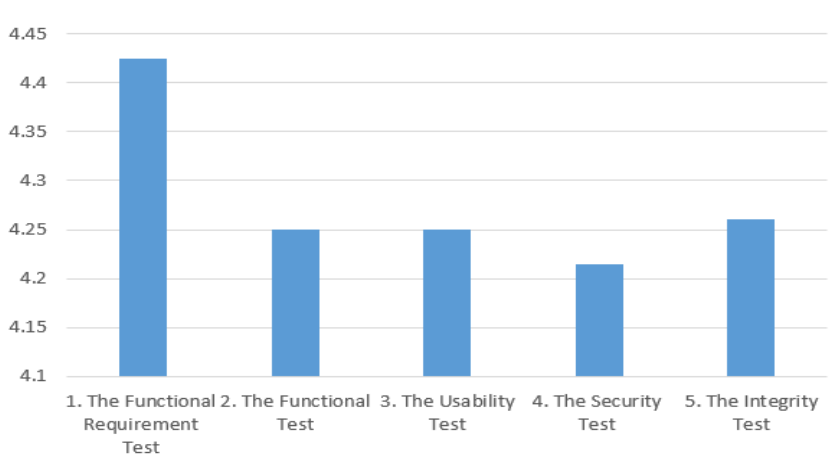

Fig. 6. The summary of the Black Box testing results 


\section{B. The assessment of the user satisfaction}

To evaluate the proposed application, the population were tourists using the AR application and the results was explained in table II.

\section{Table- II: The user satisfaction}

\begin{tabular}{l|c|c|c|} 
& $\bar{X}$ & SD & Result \\
\hline $\begin{array}{l}\text { 1. The proposed application is } \\
\text { unique and modern. }\end{array}$ & 4.59 & 0.69 & $\begin{array}{c}\text { Highest } \\
\text { level }\end{array}$ \\
\hline $\begin{array}{l}\text { 2. The proposed application } \\
\text { makes users feel close to tourist } \\
\text { attractions. }\end{array}$ & 4.58 & 0.60 & $\begin{array}{c}\text { Highest } \\
\text { level }\end{array}$ \\
\hline $\begin{array}{l}\text { 3. The screen is displayed the } \\
\text { suitability of the size, style and } \\
\text { font }\end{array}$ & 4.50 & 0.71 & $\begin{array}{l}\text { High } \\
\text { level }\end{array}$ \\
$\begin{array}{l}\text { 4. The language used is clear, } \\
\text { easy to understand. }\end{array}$ & 4.46 & 0.70 & High level \\
\hline $\begin{array}{l}\text { 5. The command menu is in the } \\
\text { right position and covers the use }\end{array}$ & 4.45 & 0.74 & High level \\
\hline $\begin{array}{l}\text { 6. The user interface design was } \\
\text { presented in the suitability of the } \\
\text { positioning in various parts } \\
\text { including images or descriptions. }\end{array}$ & 4.34 & 0.48 & High level \\
\hline
\end{tabular}

It is found that tourists are satisfied with the AR application in high level and when examined each item, it was found that the satisfaction is high level.

\section{CONCLUSION}

The aim of this project was to implement the smart navigation system using augmented reality that can use in Benchakitti Park to make a fun and knowledge for users. This project was implemented by $\mathrm{C \#}$ and Unity and applied MapBox API to enhance the point of interests (POIs). The application was composed of 2 parts, the mobile app and the admin web site developed by AngularJS 7, CSS, and JavaScript and Node.Js. The operation of the mobile application is divided into 4 parts, the user part, the navigation part, the game part and help part. The result of this project was satisfied at a good level by experts and users and the proposed system was able to navigate and to enable users to have fun. However, the further development of the premise is to improve the augmented reality model to be more accurate and focus on the UX/UI aspect more. Moreover, the Speech Recognition techniques is suggested to make it easier for users to find destinations.

\section{ACKNOWLEDGMENT}

The authors thank Suan Sunandha Rajabhat University to subsidize the financial scholarship for this project.

\section{REFERENCES}

1. Augmented reality. Retrieved November 23, 2019 https://en.wikipedia.org/wiki/Augmented_reality

2. Benjakitti Park. Retrieved November 23, 2019 https://en.wikipedia.org/wiki/Benjakitti_Park

3. John V.Pavlik and Frank Bridges. (2013). "The Emergence of Augmented Reality (AR) as a Storytelling Medium in Journalism,' Journalism \& Communication Monographs, Volume 15(1), page 4-59.

4. Harriet Mallinson. (2017). New year, new resolution': Provocative anti-smoking billboard advert 'coughs' whenever it senses cigarette smoke., Available:
http://www.dailymail.co.uk/news/article-4102944/New-year-new-resol utionsProvocative-anti-smoking-billboard-ady

5. Cabero, J., \& Barroso, J. (2016). The educational possibilities of Augmented Reality. New Approaches in Educational Research, Volume 5(1), page 44-50.

6. Parkin, S. (2016, October 23). After the success of Pokémon Go!, what is the future for augmented reality? Available: https://www.theguardian.com/technology/2016/oct/23/augmented-reali tydevelopment-future-smartphone

7. Wright, I. (2017). What Can Augmented Reality Do for Manufacturing? Available:

https://www.engineering.com/AdvancedManufacturing/ArticleID/1490 4/What-CanAugmented-Reality-Do-for-Manufacturing.aspx

8. Rehman, U., and Cao, S. (2017). "Augmented-Reality-Based Indoor Navigation: A Comparative Analysis of Handheld Devices versus Google Glass.”, IEEE Transactions on Human-Machine Systems, Volume 47(1), page. 140-151.

9. Huey, L. C., P. Sebastian, and M. Drieberg. (2011).”Augmented reality based indoor positioning navigation tool". IEEE Conference on Open Systems, IEEE. Page 256-260.

10. Kim, J. and H. Jun.(2008). "Vision-based location positioning using augmented reality for indoor navigation.", IEEE Transactions on Consumer Electronics. Volume 54(3): page 954-962.

11. Zeb, A., S. Ullah, and I. Rabbi. (2014). "Indoor vision based auditory assistance for blind people in semi controlled environments". 4th International Conference on Image Processing Theory, Tools and Applications (IPTA).

12. ShahSani, R.K., S. Ullah, and S. U. Rahman. (2017). "Automated Marker Augmentation and Path Discovery in Indoor Navigation for Visually Impaired”. International Conference on Augmented Reality, Virtual Reality and Computer Graphics. Springer, Cham. Page 427-437.

13. Tara Rustagi, Kyungjin Yoo., INDOOR AR NAVIGATION USING TILESETS., Proceedings of the 24th ACM Symposium on Virtual Reality Software and Technology., Tokyo, Japan - November 28 December 01, 2018

14. Nidhra, S. and Dondeti, J. (2012). "Black Box and White Box Testing Techniques- A Ltreature Review". International Journal of Embedded Systems and Applications (IJESA) Vol.2, No.2 [online] Available: http://airccse.org/journal/ijesa/papers/2212ijesa04.pdf

15. Amen, Bakhtiar, Mahmood, Sardasht and Lu, Joan. (2015). Mobile application testing matrix and challenges, Computer Science \& Information Technology.

16. Kularbphettong, K., Chalowattana, S., and Janpla S. The Effect of Using e-Tracking System for Small Enterprise. International Journal of Information and Education Technology, Vol. 8, No. 11, November 2018 .

\section{AUTHORS PROFILE}

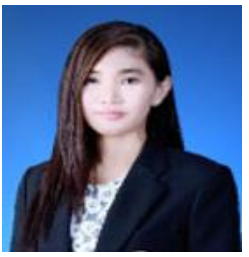

Kunyanuth Kularbphettong Assistant Professor of Computer Science Program, is working with Suan Sunandha Rajabhat University. Thailand. She is interested research in data mining, machine learning, software applications and educational learning. (e-mail: kunyanuth.ku@ssru.ac.th).

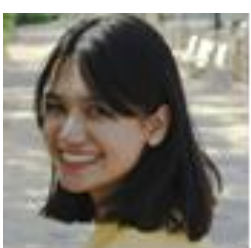

Ausanee Singkoo is the Developer of AIS Company. She is interested in Augmented Reality and mobile application. (e-mail: ausanee.si@gmail.com) 


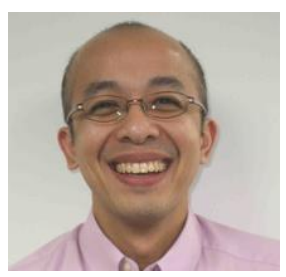

Phanu Waraporn Lecturer of Computer Science Program, A faculty member of Suan Sunandha Rajabhat University's Faculty of Science and Technology and a full-time lecturer with the undergraduate program of study in computer science, he earned the Master of Science Degree in Computer Information Systems from Assumption University (ABAC), Thailand and a Bachelor of Business Administration (Accounting) from the same university. He has spent some years attending advanced study at the doctoral level at the PhD Program in Information Technology at King Mongkut's University of Technology North Bangkok where he completed all the course works and his dissertation defense. Due to health issue, he, however, had to discontinue the study. Mr.Waraporn is currently undertaking a doctoral study with the $\mathrm{PhD}$ Program in Management of Information Technology with School of Informatics, Walailak University. His interests are in the areas of cognitive intelligent systems and language modeling and engineering, otherwise known as Natural Language Processing (NLP) in the domain of medicine especially in the palliative (end-of-life care) and genetics.

(e-mail: phanu.wa@ssru.ac.th). 